\title{
$\Delta^{\text {neverta }}$ \\ Triângulo
}

\section{IMPACTOS DAS AÇÕES DO PIBID NAS ESCOLAS DE UBERABA-MG}

\author{
IMPACTS OF THE ACTIONS OF THE PIBID IN SCHOOLS OF \\ UBERABA (MINAS GERAIS STATE)
}

\author{
Marinalva Vieira Barbosa ${ }^{1}$; Natalia Ap. Morato Fernandes ${ }^{2}$ e Juliana Bertucci Barbosa ${ }^{3}$
}

\begin{abstract}
RESUMO
Este trabalho apresenta os resultados parciais de uma pesquisa em andamento sobre os impactos das ações do Pibid nas escolas de Uberaba. A pesquisa tem como objetivo identificar mudanças introduzidas no cotidiano escolar a partir do desenvolvimento de atividades do Pibid, seja em relação à dinâmica de funcionamento da escola, aos comportamentos e atitudes dos sujeitos envolvidos, bem como em relação aos processos de ensinoaprendizagem e de formação continuada. A obtenção de dados está sendo realizada por meio de questionários, entrevistas e grupos focais tendo como sujeitos diretores, professores e alunos de escolas que receberam o PIBID, bem como pela análise de documentos como relatórios de atividades e outros registros que expressam as representações de coordenadores de área, professores supervisores, licenciandos e alunos das escolas sobre o programa. Neste trabalho serão apresentadas algumas reflexões construídas a partir dos dados obtidos nos questionários aplicados a diretores e professores das escolas pesquisadas.
\end{abstract}

PALAVRAS-CHAVE: PIBID. Educação básica. Práticas educacionais.

\begin{abstract}
This article presents the partial results of a still ongoing research on the impacts of the actions of the Pibid in Uberaba schools. The research aims to identify changes caused by the activities developed by the PIBID in everyday school life whether in relation to school working dynamics, the behavior and attitudes of those involved, as well in relation to the teaching-learning processes and continuing education. The data collection is being conducted through questionnaires, interviews and focus groups with subjects as directors, teachers and students from schools that received the PIBID. Besides, we analyzed documents such as activity reports and other records that express representations of the area coordinators, supervisors, teachers, undergraduates and students of the schools on the program. This work presents some reflections obtained from of data from questionnaires given to directors and to teachers of the schools surveyed.
\end{abstract}

KEYWORDS: PIBID. Basic education. Educational practices.

\section{INTRODUÇÃO}

Concebido pelo Ministério da Educação atendendo às atribuições legais da CAPES (Fundação Coordenação de Aperfeiçoamento de Pessoal de Nível Superior), o Pibid (Programa Institucional de Bolsas de Iniciação à Docência) visa induzir e fomentar a formação inicial e continuada de profissionais do magistério (Lei n ${ }^{\circ} 11.502$, de 11 de julho de 2007). Para tanto, dentre as suas principais metas, duas focalizam a escola básica e visam

\footnotetext{
${ }^{1}$ Universidade Federal do Triângulo Mineiro. E-mail: marinalvav@gmail.com

${ }^{2}$ Universidade Federal do Triângulo Mineiro. E-mail: natmorato@gmail.com

${ }^{3}$ Universidade Federal do Triângulo Mineiro. E-mail: julianabertucci@gmail.com
} 
promover impactos importantes, uma vez que buscam: a) Promover a melhoria da qualidade da educação básica; b) Articular e integrar a educação superior e a educação básica do sistema público de ensino.

De acordo com relatórios da CAPES, esses objetivos estão sendo desdobrados pelos projetos institucionais das IES nas seguintes ações:

a) incentivo à mudança e à inovação; b) elevação do desempenho dos alunos e motivação dos professores; c) bolsistas Pibid como inspiração para alunos das escolas públicas que buscam cursos superiores que não estavam em seu projeto de vida; d) apoio a vestibulandos e preparação para o ENEM; e) uso, renovação e adequação de laboratórios de Física, Ciências, Química, Informática; f) revitalização de bibliotecas; g) feiras de ciências, mostras de literatura e outras (BRASIL, 2011, p. 05).

Orientados pelos objetivos e metas definidos pela CAPES, na região de Uberaba o Pibid começou com o projeto institucional da UFTM (Universidade Federal do Triângulo Mineiro) aprovado em 2009. Em 2011, ainda na UFTM foi aprovado o segundo projeto institucional e, neste momento, temos também projetos de iniciação à docência sendo desenvolvido pelo IFTM (Instituto Federal do Triângulo Mineiro) e pela UNIUBE (Universidade de Uberaba). Em 2013, foi apresentando o terceiro projeto institucional da UFTM que reuniu todos os cursos de licenciaturas da UFTM: Letras (Português, Inglês e Espanhol), Geografia, História, Ciências Biológicas, Matemática, Química e Fisica. Na UFTM, atualmente são 10 subprojetos que, juntos, oferecem 340 bolsas de Iniciação à Docência, 63 de Supervisão, 24 de coordenação de área, 03 de coordenação de gestão e 01 de coordenação institucional - perfazendo um total de 432 bolsistas. A terceira edição do programa está sendo desenvolvida em cerca de 30 escolas públicas municipais e estaduais com a participação de aproximadamente 5.000 alunos dessas escolas, como apontam os relatórios enviados a CAPES no último ano.

No plano nacional, até 2014 a CAPES vinha trabalhando para transformar o Pibid num Programa permanente, com caráter de política de Estado para a melhoria da formação inicial e continuada dos professores da educação básica e, conforme assinalado, também pretende a melhoria do ensino básico a partir de ações coordenadas e complementares entre universidade e escola. No relatório das atividades de 2009 a 2011, disponível na página da própria CAPES, encontra-se a seguinte afirmação: 
O Pibid oferece bolsas para que alunos de licenciatura exerçam atividades pedagógicas em escolas públicas de educação básica, contribuindo para a integração entre teoria e prática, para a aproximação entre universidades e escolas e para a melhoria de qualidade da educação brasileira. Para assegurar os resultados educacionais, os bolsistas são orientados por coordenadores de área - docentes das licenciaturas - e por supervisores - docentes das escolas públicas onde exercem suas atividades. O diálogo e a interação entre licenciandos, coordenadores e supervisores geram um movimento dinâmico e virtuoso de formação recíproca e crescimento contínuo (BRASIL, 2011, p. 4).

O Pibid é um Programa que chamou para si a responsabilidade de criar as condições para que a relação entre universidade e escola se estabeleça com o intuito de melhorar as condições de ensino básico e a formação dos futuros professores para essa mesma escola. Essa melhoria, acredita-se, ocorrerá porque a universidade, por meio dos projetos, passa a atuar com os licenciandos e professores no cotidiano das escolas e, as escolas, por meio dos seus professores, transformam-se em coformadores dos futuros docentes. "Assim, a Capes incentiva as instituições de educação superior a reconhecerem nas escolas públicas um espaço de produção e de apropriação de conhecimento, tornando-as, simultaneamente, partícipes e beneficiárias dos estudos e dos projetos desenvolvidos” (BRASIL, 2011, p. 01).

Entretanto, ao mesmo tempo, pesquisas produzidas no campo educacional nas últimas décadas têm denunciado de modo contundente os problemas e fracassos da escola básica na realização de seu objetivo principal: dar aos alunos condições de acesso, por meio do conhecimento, aos bens culturais, sociais e políticos da nossa sociedade. Aliás, a criação do Programa é uma busca de respostas e soluções para esses problemas. Tais estudos também mostram que tradicionalmente as políticas que visam à superação desses problemas e fracassos quase sempre são decisões ou pacotes prontos, impostos à comunidade escolar de cima para baixo.

Em tais condições, dois problemas historicamente têm emergido: de um lado, os professores não se apropriam das mudanças propostas como um projeto próprio ou coletivo, mas somente como uma ordem a ser cumprida; de outro lado, as políticas, pensadas em forma de pacotes, são genéricas porque visam abranger um público de diferentes regiões. Isso, muitas vezes, impede que sejam adequadas às especificidades e necessidades de cada região.

Visando a busca por espaços de autonomia na escola que sustentem sua função educativa, de maneira que esta possa gerar transformações, primeiramente na sala de aula e, depois na sociedade, PÉREZ GÓMEZ $(1998,26)$ afirma que: 
É preciso transformar a vida da aula e da escola, de modo que se possam vivenciar práticas sociais e intercâmbios acadêmicos que induzam à solidariedade, à colaboração, à experimentação compartilhada, assim como a outro tipo de relações com o conhecimento e a cultura que estimulem a busca, a comparação, a crítica, a iniciação e a criação.

Diante disso, para esta pesquisa, assumimos que o Pibid é uma política pública com diretrizes que, se organizadas com dados contextuais, poderá permitir a consideração das especificidades e necessidades da escola básica de cada região do Brasil. Ou seja, trata-se de um Programa que, ao envolver escola básica e universidade, contém as condições necessárias para pensar a escola a partir de uma perspectiva contextualizada.

Assim, considerando as dimensões que adquiriu, torna-se fundamental a realização de pesquisas que mensurem o real impacto das ações desse Programa nas escolas. Um estudo desta natureza poderá oferecer elementos para as IES da região planejarem seus projetos e, sobretudo, será um importante indicativo para apresentar à CAPES a título de orientação sobre a qualidade e a efetividade das políticas implementadas.

No âmbito do Programa em Uberaba, ao longo dos anos de ações nas escolas, têm emergido manifestações diversas quanto aos impactos dos subprojetos nas escolas, desde via relatórios de supervisores, licenciandos e coordenadores, como manifestações diversas em reuniões pedagógicas e eventos promovidos pelas escolas e pelos órgãos responsáveis, como Secretaria Municipal de Educação e Superintendência Regional de Ensino. Ainda que tais indícios demonstrem mudanças na escola e destinem certa importância destas mudanças ao Programa, tais dados ainda não foram levantados ou sistematizados, o que demonstra que, o levantamento e sistematização destas primeiras constatações trariam importantes subsídios ao andamento do Programa nas instituições de ensino locais, bem como em âmbito mais geral do Programa nacional.

Além disso, esse estudo se justifica porque, embora se trate de um Programa novo, não é difícil constatar que estudos já foram produzidos sobre os impactos do Pibid na formação dos licenciandos, futuros ou já professores da escola básica. Existem muitas lupas voltadas para as práticas formativas estabelecidas na Universidade para os licenciandos, porém, pouco se propôs a produzir, como resultado de pesquisa formal, sobre os impactos da entrada da universidade nas escolas via atividades e subprojetos do Pibid. 
Os resultados alcançados também poderão ser tomados como conhecimento sobre as necessidades formativas dos futuros ou já professores da educação básica e sobre possibilidades de interferir nessa formação a partir dos retornos que a própria escola dá aos propósitos do Programa. Especificamente, permitirão gerar um quadro teórico reflexivo, fundamentado em dados retirados da realidade concreta das escolas, sobre as compreensões, a cultura, as formas de transmissão vigentes na escola básica e que, por sua vez, também impactam nos objetivos e metas das políticas que visam à transformação da escola básica.

Nesse sentido, essa pesquisa tem como objetivo fazer um diagnóstico e analisar os impactos das ações do Programa Institucional de Bolsas de Iniciação à Docência nas escolas de Uberaba, na região do Triângulo Mineiro. Especificamente, porque formado por uma equipe interdisciplinar, o objetivo será diagnosticar e analisar os impactos deste Programa nas escolas que acolhem subprojetos das áreas de Geografia, História, Ciências Biológicas, Química, Matemática, Física, Língua Portuguesa, Língua Inglesa e Língua Espanhola e também subprojetos de abordagens interdisciplinares.

Como objetivos específicos, temos:

- Fazer um levantamento das alterações introduzidas no dia a dia das direções escolares em função das atividades do Pibid.

- Investigar se as atividades do Pibid ampliam e/ou mudam as formas de cooperação e de conflitos entre professores da escola básica (supervisores ou não) e professores coordenadores do Pibid.

- Diagnosticar se as atividades do Pibid aprimoram ou não a capacidade e o desempenho de leitura e escrita de textos dos professores supervisores do Pibid nas diversas áreas de conhecimento.

- Fazer um levantamento e análise das dificuldades facilidades que professores supervisores apresentam ao procurarem utilizar os conhecimentos teóricos adquiridos durante a participação no Pibid em sua prática cotidiana.

- Apontar se o Pibid está promovendo mudanças nas representações que os alunos da escola básica apresentam sobre os conteúdos de ensino das disciplinas escolares, bem como na sua participação nas atividades cotidianas de sala de aula e escolar.

- Avaliar se o aluno da escola básica, ao participar das atividades do Programa e conviver com os alunos e professores universitários, passa a vislumbrar a possibilidade de entrar numa universidade pública. 
- Investigar se há mudança no desempenho de alunos que participam das atividades do Pibid.

\section{METODOLOGIA DE TRABALHO}

A metodologia adotada para a execução da pesquisa fundamenta-se em três linhas que se complementam:

1) Levantamento das leituras e intepretações feitas por coordenadores, supervisores e licenciados nos relatórios produzidos para as coordenações institucionais sobre a recepção e execução das atividades do Pibid nas e pelas escolas.

2) A produção de dados por meio da aplicação de questionários, realização de entrevistas e grupos focais com professores e alunos das escolas que acolhem o Pibid para delinear as leituras, representações, interpretações e modo de receber e perceber que a comunidade escolar faz das propostas e atividades do Pibid.

3) Construção de um diagnóstico e análise dos impactos do Pibid nas escolas de Uberaba a partir da contraposição dos dados levantados dos relatórios e produção de dados por meio de questionários, entrevistas e grupos focais.

\section{Análise dos relatórios produzidos no âmbito do Pibid}

Os relatórios produzidos por licenciandos/supervisores e coordenadores objetivam registrar os resultados, as dificuldades e avanços alcançados no âmbito dos subprojetos do Pibid. Elaborados a partir das interações que acontecem no contexto escolar, essas produções registram os acontecimentos a partir da interpretação que os bolsistas fazem dos retornos dados por professores, alunos e direções das escolas que acolhem o Pibid.

Na UFTM, são esses relatórios que oferecem subsídios para que a coordenação institucional produza o relatório geral, a ser encaminhado a CAPES, sobre os resultados, dificuldades e avanços do Pibid. Tais produções são marcadas, portanto, pelas exigências, pelas formas de interlocução e pelos objetivos que determinam sua produção. Isso significa que, dessa perspectiva, o discurso produzido sobre a escola não é um objeto autônomo. É um gênero, logo um objeto múltiplo e que envolve a interação entre sujeitos constituídos nas relações, exigências e regulações próprias do funcionamento de um programa como o Pibid. 
Nesse caso, assumimos que, embora seja uma produção regrada e com vistas a oferecer garantias para as instâncias superiores de que o Programa funciona, os conflitos de posições, vozes e objetivos ficam demarcados na materialidade linguísticas dos relatórios porque o sentido de um discurso não está associado simplesmente à palavra, nem aos enunciados, mas depende, de alguma forma, exatamente, da enunciação dos enunciados, o que, por sua vez, depende das condições de produção constitutivas do discurso.

Assim, o objetivo desta parte do estudo visa compreender os impactos do Pibid nas escolas, tendo como base os relatórios do produzidos nos últimos dois anos por licenciandos e supervisores. Buscamos observar em tais registros: a) as peculiaridades de cada escola, os ritmos dos vários grupos e processos que permitam a dinâmica cotidiana; b) a participação de todos os segmentos que compõem a escola nas atividades e projetos do Pibid, inclusive pais e todos aqueles que, de alguma forma, tem a ver com a dinâmica da escola; c) as propostas do Pibid, observando se estão sendo configuradas dentro das mais amplas que são desenvolvidas em cada escola; d) as dificuldades apresentadas pela comunidade escolar no momento de realizar as atividades do Programa; e) as respostas das escolas a partir das demandas postas pelos subprojetos do Pibid.

Feito esse levantamento nos relatórios de todas as áreas envolvidas na pesquisa, construímos um quadro analítico que demarca como e quais são as diferenças e similaridades existentes - e registradas pelas equipes pibidianas - nas práticas de professores, direções e alunos de cada escola participante do Pibid e, consequentemente, desta pesquisa. Procuramos com tal levantamento, indícios que demonstrem como "para" e "na" universidade - e consequentemente para a CAPES - estão sendo construídas leituras acerca dos impactos (ou não) do Pibid na escola básica de Uberaba.

\section{A produção de dados por meio da aplicação de questionários, realização de entrevistas e grupos focais.}

A metodologia adotada para esta etapa da pesquisa fundamenta-se em quatro eixos que se complementam e orientam a elaboração de perguntas para a produção de dados - por meio da aplicação de questionários, entrevistas semiestruturadas e pela gravação de interações verbais desenvolvidas em grupos focais - em todas as áreas da escola básica de Uberaba alcançadas por subprojetos do Pibid. São eles: 
1) se o Pibid está promovendo mudanças nas representações que os alunos da escola básica apresentam sobre os conteúdos de ensino.

2) se está ocorrendo mudanças nas posturas e práticas de ensino dos professores que, não sendo supervisores, convivem com os integrantes e participam das atividades do Programa.

3) se o aluno da escola básica, ao participar das atividades do Programa e conviver com alunos e professores universitários, passa a ver a universidade pública como lugar para fazer sua formação universitária.

4) os impactos das atividades do Pibid nas práticas de leitura e escrita dos professores supervisores.

Com base nesses quatro eixos, a equipe de pesquisadores tem organizado as perguntas de modo que, no momento de coleta e análise dos dados, seja possível estabelecer as relações necessárias para compreender os impactos do Programa nas escolas parceiras.

Para tanto, foi adotada uma metodologia de base qualitativa e etnográfica, portanto, voltada para descrição e interpretação dos fenômenos pesquisados para construir sentidos e compreensões acerca de uma realidade complexa. O desafio de uma pesquisa, antes de tudo, é fazer o relato de uma dada situação muitas vezes já conhecida. Neste caso, a obrigação não é com originalidade, mas com a construção de um modo diferente de olhar e pensar determinados acontecimentos.

De acordo com LÜDKE e ANDRÉ (1986), a pesquisa qualitativa permite ao pesquisador construir esse olhar diferenciado porque também permite chegar mais perto da perspectiva dos sujeitos por meio do uso de observação direta e ancorada também nos conhecimentos e experiências pessoais. Esse saber ajuda na interpretação dos fenômenos estudados. O tipo etnográfico de pesquisa qualitativa pressupõe o contato direto do pesquisador com o "objeto" de estudo, gerando assim, diversos dados descritivos baseados especialmente na observação de situações, pessoas ou grupos. A partir desta observação, pode-se fazer um intercâmbio constante com a análise dos dados. O método básico deste tipo de pesquisa é a observação participante, mesmo utilizando-se de fontes variadas e técnicas diversas de coleta de dados.

A coleta do corpus, por essa perspectiva, baseia-se nas características elencadas por BOGDAN e BIKLEN (1992), que são: a) pesquisador como principal instrumento de pesquisa e o ambiente natural como fonte direta dos dados. No caso dessa pesquisa, o ambiente serão as escolas em que os projetos do Pibid estão sendo realizados; b) o corpus é 
formado também pela descrição de pessoas, situações e acontecimentos, podendo haver a transcrição de depoimentos; c) o processo assume maior importância que o produto, já que este não precisa ser numericamente comprovado; d) necessidade de levar em consideração as formas de pensar dos participantes e os significados que eles atribuem a vida e as ações que praticam no contexto em que estão inseridos.

Como a pesquisa tem como principal objeto de análises discursos de professores e alunos das escolas de Uberaba, esses sujeitos serão convidados a responderem questionários contendo questões que visem diagnosticar e avaliar a qualidade das ações do Programa. A aplicação de questionário é um instrumento importante, pois se trata de um recurso que permite a obtenção imediata de informações que podem ser posteriormente analisadas e que, neste caso, podem abrir um leque de possibilidades sobre os impactos do Pibid.

O questionário representa um dos instrumentos básicos para a coleta de dados dentro da perspectiva de pesquisa qualitativa. Assim, após a aplicação dos questionários e uma análise preliminar dos dados fornecidos, foram selecionados alunos e professores das escolas para a realização de entrevistas. Foi adotada a modalidade de entrevista semiestruturada porque esta possui uma forma de organização e funcionamento flexível, o que permite ao pesquisador fazer adaptações a partir das situações que surgem na realização. Por outro lado, a entrevista semiestruturada garante que sejam estabelecidos no seu roteiro pontos comuns a serem abordados pelos informantes das diferentes escolas e áreas abrangidas pelo Pibid, permitindo que se estabeleçam bases comparativas.

Além dos questionários e entrevistas, também estão sendo organizados grupos focais com o objetivo de obter informações aprofundando a interação entre os participantes da pesquisa por meio da temática da pesquisa. De acordo com MINAYO (2008, p. 269):

O valor principal dessa técnica fundamenta-se na capacidade humana de formar opiniões e atitudes na interação com outros indivíduos (Krueger, 1988). Nesse sentido, o uso dos grupos focais contrasta com a aplicação de questionários fechados e de entrevistas em que cada um é chamado a emitir opiniões individualmente.

No escopo da pesquisa, planeja-se a realização dos grupos focais com professores das escolas parceiras do Pibid, selecionados pelos pesquisadores a partir da realização das entrevistas. A utilização dessa técnica contribui para complementar as informações coletadas nos questionários e entrevistas, particularmente em relação à percepção dos professores sobre os impactos do Pibid nas escolas, podendo aflorar destes consensos ou divergências que serão 
cotejados com os dados coletados por meio dos outros instrumentos, contribuindo, assim, para as análises dos pesquisadores.

Assim, essa parte do corpus é pertinente e fornece um material importante para compreender as relações, as representações, as concepções e práticas que estão sendo gestadas ou questionadas no cotidiano das escolas em função das atividades do Pibid. Neste caso, o objetivo é fazer emergir as leituras e as representações que a própria escola faz de propostas oficiais como as do Pibid e, principalmente, como lê a sua própria participação ou não nessas propostas.

\section{Sobre a sistematização e análises dos dados}

No que tange aos procedimentos de seleção e análise dos dados, foi adotada a concepção indiciária, tal como proposta pelo italiano Carlo GINZBURG (1999). A localização no campo indiciário significa que esta é uma pesquisa que não terá, em todas as suas etapas, a sua relevância sustentada na repetição de situações. A pesquisa qualitativa, etnográfica e indiciária traz em sua gênese a refutação à concepção de rigor construído por meio da quantidade. Quanto mais os traços individuais são considerados pertinentes, maior é o afastamento do campo científico que trabalha com dados visíveis, repetíveis e comprováveis.

Porém, um indício não deixa de ser complexo porque se organiza e se reorganiza na fronteira com outros indícios, com outros sentidos e valores. Seu valor e significância são construídos numa espécie de teia. A observação do contexto de produção é fundamental porque o objetivo não é confirmar a validade do dado pela repetição, mas pela relação de complementaridade que pode ser estabelecida com outros e entre dados.

A construção do corpus segue um plano flexível e dialógico; dito de outro modo, as produções serão analisadas considerando a perspectiva histórica, cultural e social que sustentam sua produção no contexto escolar e acadêmico. Importa considerar nas análises dos relatórios que são produções regradas, orientadas por um conjunto de coerções e objetivos que são próprios da gestão de um programa institucional como o Pibid. Na produção dos dados por meio das entrevistas e questionários, é importante também pôr em relevância as diferenças de posições assumidas por professores e alunos da escola e da universidade.

Por se tratar de uma pesquisa qualitativa, conforme já assinalado, uma característica fundamental da análise dos dados é o dialogismo e a reflexibilidade. Com esses conceitos 
demarca-se que é dada especial atenção à forma como elementos linguístico-discursivos, sociais, culturais, políticos e teóricos influenciam de maneira conjunta no processo de desenvolvimento do conhecimento (interpretação), nas estratégias narrativas (formas de apresentação), que marcam a produção dos textos e reflexões (autoridade, legitimidade) sobre o Pibid nas escolas (ESTEBAN, 2010).

No que tange a produção de conhecimento teórico sobre os impactos do Pibid nas escolas de Uberaba, como a equipe de pesquisadores é interdisciplinar, verificamos que é a partir da sistematização dos dados que as interpretações e conceptualizações são construídas. Dito de outro modo, não foi adotada uma linha teórica específica como ponto de partida, mas sim, uma perspectiva de investigação baseada nos conhecimentos, saberes e experiência da equipe e nos dados interpretados, conceitualizados. Nesse sentido, a formulação teórica resultante desta pesquisa advém do debate, das discussões em grupo, buscando-se ser não só um meio de explicar a realidade apresentada pelos sujeitos de pesquisa sobre o Pibid nas escolas, mas também ser uma produção de elementos orientadores de ações futuras.

\section{RESULTADOS PARCIAIS}

\section{Primeiras observações sobre o questionário dos Professores}

Em relação à aplicação de questionários dos professores, tivemos a participação de 40 professores de 12 escolas públicas de Uberaba-MG.

Com relação ao perfil desses docentes, os dados nos mostram que $75 \%$ são do sexo feminino; 91\% têm idade acima de 25 anos, concentrados entre 25 e 49 anos; $85 \%$ possuem graduação na modalidade Licenciatura; $82,5 \%$ cursaram a educação básica em escola pública e $62 \%$ cursaram a graduação em IES particular. Com relação à pós-graduação, $60 \%$ possuem especialização, 10\% mestrado e 30\% não cursou pós-graduação.

Quanto ao tempo de atuação no magistério, verificamos que $20 \%$ têm até 3 anos e a maioria $(67,5 \%)$ dos respondentes possui entre 7 e 25 anos de atuação no magistério. Percentualmente, 57,5\% trabalham em apenas uma escola, 35\% em duas escolas e 7,5\% em três ou mais escolas. 52\% atuam no Ensino Médio e 35\% no Ensino Fundamental II. A maioria possui carga horária de $21 \mathrm{~h}$ a $40 \mathrm{~h}$ semanais de trabalho.

Dos quarenta professores que responderam ao questionário, $60 \%$ deles nunca atuaram como bolsista do Pibid, 32,5\% atuam ou já atuaram como supervisores e 7,5\% já atuaram 
como bolsistas de iniciação à docência. Dentre os que já atuaram no Pibid, 75\% apontam a formação continuada como sua principal motivação para atuar no Pibid.

Sobre a percepção dos professores a respeito dos impacto do Pibid na escola temos os seguintes resultados gerais:

- $\quad 75 \%$ consideram que as atividades do Pibid impactaram muito positivamente na mudança de atitudes e comportamentos dos alunos da escola que participaram de atividades. As mudanças percebidas foram principalmente em relação ao engajamento em atividades da escola e aumento da motivação e interesse dos alunos pelas aulas.

- $\quad 57,5 \%$ consideram que o Pibid contribuiu para a ampliação do interesse do aluno pelo ingresso na universidade pública;

- $\quad 89 \%$ afirmam que a participação no Pibid permitiu que refletissem sobre a sua prática docente (entre os professores que atuam ou já atuaram como supervisores do Pibid);

- $\quad 89 \%$ desse grupo afirma que as atividades do Pibid impactam muito na aprendizagem de conteúdos escolares dos seus alunos participantes de atividades dos subprojetos;

- $\quad 94,5 \%$ consideram que as atividades do Pibid impactaram muito na formação docente dos licenciandos envolvidos nos projetos.

Entre as atividades que mais impactaram na aprendizagem de conteúdos escolares pelos alunos foram apontadas como mais relevantes:

1) Trabalhos fora do ambiente escolar (Trabalhos de campo, visitas monitoradas, estudos do meio);

2) Oficinas;

3) Intervenções em sala de aula com a participação de licenciandos e supervisor;

4) Feiras de conhecimento (Gincanas, Exposições).

Sobre as atividades de maior relevância para a aprendizagem de temas interdisciplinares foram destacadas:

1) Feira de conhecimentos (Gincanas, Exposições);

2) Trabalhos fora do ambiente escolar (Trabalhos de campo, visitas monitoradas, estudos do meio);

3) Oficinas e Intervenções em sala de aula com a participação de licenciandos e supervisor;

4) Minicursos. 
Quando perguntados sobre as atividades que mais impactaram na aquisição de procedimentos de estudos, as respostas foram:

1) Intervenções em sala de aula com a participação de licenciandos e supervisor;

2) Trabalhos fora do ambiente escolar (Trabalhos de campo, visitas monitoradas, estudos do meio);

3) Monitorias em sala de aula;

4) Feira de conhecimentos (Gincanas, Exposições).

Para 79\% dos professores desse grupo, o envolvimento dos outros professores da escola em relação ao Pibid é baixo. Em relação à direção da escola $74 \%$ consideram que há um alto envolvimento. Sobre a parceria entre universidade e escola, 50\% desses professores consideram que o Pibid contribuiu muito para o estabelecimento ou fortalecimento dessa parceria.

Para 40\% dos professores da Educação Básica participantes do Pibid, a principal contribuição do programa é a oportunidade de atuação profissional pelos licenciandos. Por fim, ainda em relação a esse grupo: (i) 74\% consideram que o Pibid ampliou muito sua capacidade de leitura e escrita de textos; (ii) 95\% consideram que os conhecimentos teóricos adquiridos durante a participação no Pibid ajudam muito em sua compreensão, planejamento e desenvolvimento de suas práticas de ensino.

\section{Primeiras observações sobre o questionário dos alunos}

Em relação aos alunos, responderam ao questionário 276 alunos de 12 escolas públicas de Uberaba-MG. Tais participantes (alunos, possuem o seguinte perfil: (i) quanto ao gênero, $56 \%$ são do sexo masculino e $42 \%$ feminino; (ii) quanto ao período escolar: $51 \%$ estão no Ensino Fundamental e 48\% no Ensino Médio; (iii) quanto à faixa etária, 47\% estão entre $12 \mathrm{e}$ 14 anos; 45\% entre 15 e 18 anos; 3\% têm idade de 11 anos. No questionário, também foi perguntado sobre imagem que cada aluno tem de si mesmo, nesse item verificamos que: $32 \%$ se definem como bons alunos; 64\% se consideram um pouco bom.

Sobre a escola, 94\% consideram que estuda numa escola boa; $5 \%$ consideram que a escola que estuda não é boa; $93 \%$ consideram a formação escolar importante; $5 \%$ não. 94\% pretendem fazer universidade, $69 \%$ declaram preferência pela universidade pública. Contudo, $76 \%$ afirmam que não pretende seguir a carreira docente e $61 \%$ afirmam que essa carreira apresenta vantagens e desvantagens na mesma proporção. 
A maioria dos alunos participantes da pesquisa, possui entre 07 meses a um ano das atividades do Pibid. Por fim, em relação às ações do Pibid na rotina escola, afirmam que o Programa impactou positivamente tanto para ter mais conhecimento quanto interesse pela disciplina. Apontaram que o Programa motiva os estudos, influencia no interesse pela disciplina, incentiva o gosto pela leitura e contribui para a valorização do trabalho do professor. A maioria também sinalizou que o Pibid influenciou com mais força no interesse em estudar a disciplina ligada ao subprojeto que participou.

\section{CONSIDERAÇÕES FINAIS}

Nesse estudo apresentamos os caminhos de uma pesquisa em desenvolvimento voltada ao diagnóstico dos impactos das ações do Pibid nas escolas de Uberaba. Desse modo, os dados apresentados são, ainda, parciais e sua análise preliminar.

No entanto, os dados obtidos nessa pesquisa apontam que o Pibid possui os elementos necessários (porque envolve o licenciando em formação, o professor universitário e o professor e o aluno da escola básica) para criar as condições para realização de uma formação inicial consistente, articulada e que, sendo realmente fruto do diálogo entre universidade de escola, pode produzir mudanças significativas nas práticas de ensino e aprendizagem desenvolvidos na escola.

Assim, os resultados descritos no tópico anterior, ainda que preliminarmente, permitem afirmar que esse Programa criou as condições necessárias à transformação das relações e representações que alunos e professores fazem da escola e de si como sujeitos de conhecimento.

\section{REFERÊNCIAS}

BOGDAN, R.C.; BIKLEN, S.K. Qualitative research for education: an introduction to theory and methods. 2. ed. Boston: Allyn and Bacon, 1992. 262 p.

BRASIL. Ministério da Educação. Coordenadoria de Aperfeiçoamento de Pessoal de Nível Superior. Relatório de Gestão PIBID. In:

http://www.capes.gov.br/images/stories/download/bolsas/DEB_Pibid_Relatorio2009_2011.pdf.

ESTEBAN, M. P. S. Pesquisa qualitativa em educação: fundamentos e tradições. Porto Alegre: Mc Graw Hill \& Artmed, 2010. 
GINZBURG, C. "Sinais: raízes de um paradigma indiciário". In: Sinais. São Paulo: Companhia das Letras, 1999. . Mitos, Emblemas,

LÜDKE, M.; ANDRÉ, M.E.D.A. Pesquisa em educação: abordagens qualitativas. São Paulo: EPU, 1986. 99 p.

MARIN, A. J. (et al). Desenvolvimento profissional docente e transformações na escola. Revista Pro-posições, v. 1. n. 4. São Paulo, 2000.

MINAYO, Maria C. de S. O desafio do conhecimento. 11. ed. São Paulo: Hucitec, 2008.

PÉREZ GÓMEZ, A. I. As Funções Sociais da Escola: da reprodução à reconstrução crítica do conhecimento e da experiência. In: GIMENO SACRISTÁN, J.; PÉREZ GÓMEZ, A. I. Compreender e transformar o ensino. 4. ed. Porto Alegre: ArtMed, 1998.

RECEBIDO EM: 15/03/2016

APROVADO PARA PUBLICAÇÃO: 29/11/2016 